\title{
De Lugones a Marx: el proceso de politización e inserción en el campo intelectual de Luis Franco, 1920-1930
}

\author{
Pablo Torres \\ Universidad Nacional de Rosario. Investigaciones Socio Históricas Regionales - \\ Consejo Nacional de Investigaciones Científicas y Técnicas \\ pablo.l.torres86@gmail.com \\ ORCID: 0000-0003-3563-2633
}

Title: From Lugones to Marx: Luis Franco's Process of Politicization and Insertion in the Intellectual Field, 1920-1930.

Resumen: El objetivo de este trabajo es analizar el proceso de inserción en el campo intelectual de Luis Franco, prestando atención a sus ámbitos de formación y a su participación en algunas revistas literarias y culturales. También nos abocaremos a pensar cómo fue el acercamiento de este escritor al mundo de la política, atendiendo a cómo este cruce se plasmó en su obra y analizando sus reflexiones en torno a las responsabilidades del intelectual y a las funciones del arte.

Palabras clave: Luis Franco - politización - arte

Abstract: The aim of this article is to analyze Luis Franco's process of insertion in the intellectual field, paying attention to his intellectual training and his participation in some literary and cultural journals. It also tries to explain how this writer approached the world of politics, focusing on the way in which the interaction between arts and politics was reflected in his work and in his

DOI: https://doi.org/10.46688/ahmoi.n20.344

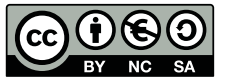

Obra bajo licencia Creative Commons 4.0 International (Atribución - NoComercial - Compartirlgual) 
considerations about the responsibilities of the intellectual and the social functions of art.

Key words: Luis Franco - politicization - art

Recepción: 6 de octubre de 2021. Aceptación: 12 de diciembre de 2021 .

$$
* * *
$$

\section{Introducción}

Luis Leopoldo Franco (1898-1988) fue un poeta saludado desde muy joven por la crítica. Fue, además, un ensayista que, con ademanes bruscos y verba filosa, intentó pensar los grandes dramas de la Argentina y escrutó gran parte de la historia nacional del siglo XIX y XX. Rápidamente fue reconocido y supo vincularse con figuras centrales del mundo intelectual argentino, dejando una obra sumamente vasta, que incluye tanto ensayos como cuentos y poesía. Sin embargo, a lo largo de su vida, Franco fue tomando distancia, alejándose de ciertos espacios de consagración del mundo intelectual y, en la actualidad, no es fácil toparse con sus libros. Es un autor que hoy circula como un murmullo casi inaudible en pequeñas tribus políticas y académicas, como una perla brillosa que se destaca en el "indice oculto" de nuestra cultura.

Apenas una serie de trabajos se han dedicado a desbrozar parte de su trayectoria, de sus aportes a la historiografia o su obra literaria. Entre los primeros estudios dedicados a Franco podemos encontrar la biografia escrita por Beatriz Correas (1962), que nos permite un primer acercamiento a su itinerario, y el ensayo de David Viñas (2007), publicado originalmente en 1984, valioso para pensar su inserción en el mundo literario de los años 20. En las últimas décadas aparecieron una serie de trabajos que retratan determinados aspectos de su figura. Entre ellos, podemos mencionar el libro de Guillermo Parson (2007), que intenta englobar diferentes cuestiones de su trayectoria intelectual y política; el escrito de Jorge Tula sobre su poesía (2000); los textos de Daniel Campione (2008), Guillermo Korn (1997) y Omar Acha (2009) -aunque este último no le dedica un trabajo particular, sino que piensa su aporte en el marco de la historiografia trotskista-, que nos ofrecen algunas aristas para pensar la lectura de la historia realizada por Luis Franco, como así también los autores y las obras que marcaron su proceso de formación intelectual. Por último, la investigación de Horacio Tarcus sobre la "Hermandad" (2009), se vuelve un texto clave para problematizar los años de formación del poeta como su inserción en el mundo intelectual en la década de 1920.

Si bien estos trabajos nos sirven como guía, creemos que es necesario 
seguir profundizando el análisis sobre su itinerario para trazar un mapa más minucioso en torno a su formación, las revistas de las que formó parte y con las cuales colaboró, las editoriales en las que orbitó y las redes intelectuales que construyó durante décadas de trabajo. En este artículo nos abocaremos a reconstruir el primer tramo del itinerario de Franco, dando cuenta del proceso de inserción en el mundo intelectual, como así también de su politización, entre los años 20 y 30, para poner en tensión esa imagen que se construyó sobre su figura -y él supo alimentar con esmero- como un paria intelectual, un perdido esquimal de la cultura. En la confección de esa imagen pareciera tomarse la posición descentrada de Luis Franco de los años 70 y 80 como una constante, posible de ser encontrada casi desde el comienzo de su derrotero. Sin embargo, sostenemos que hacer foco en sus primeros pasos en el mundo cultural durante los años 20 y 30 nos permite encontrar a un personaje que supo gozar de cierta centralidad en ese ámbito, llegando a circular por un sinfin de editoriales y a colaborar en prestigiosas revistas y publicaciones de importancia. Así, el lugar marginal que Franco llegó a ocupar durante las últimas décadas de su vida puede ser pensado como el resultado de un paulatino proceso de descentramiento, que obedeció a múltiples causas. En primer lugar, a una apuesta de Franco, quien creyó ver en la distancia respecto de ciertos ámbitos la posibilidad de proyectar un espacio de libertad y autonomía. A este proceso también contribuyó su opción política de acercarse al trotskismo -una tradición política que durante buena parte del siglo XX no contó con grandes amarres sociales o importantes aparatos culturales-, a lo que por último se agrega ese gesto iconoclasta, que tanto lo caracterizó y que se plasmó en su disposición a maltratar o fustigar a toda figura venerable del mundo de la literatura y la intelectualidad. De manera paradojal, Franco hizo casi el movimiento contrario al que sueñan tantos intelectuales: desde cierto lugar de reconocimiento optó por escabullirse a tierras más vírgenes y periféricas de la cultura.

\section{De Belén a Buenos Aires: sus primeros pasos en el campo intelectual}

Luis Franco nació en 1898 en un pequeño poblado de la provincia de Catamarca, llamado Belén. Su infancia transcurrió entre la naturaleza y sus primeras lecturas que abarcaron el viejo y nuevo testamento, Sarmiento, Cervantes y Lugones entre otros. Como hijo de una familia medianamente acomodada, tuvo una vida tranquila, hasta la temprana muerte de su padre. Algunos años después, en el marco de cierta precariedad económica de la familia, su madre decidió trasladarse a la capital provincial para que sus hijos varones pudieran realizar estudios secundarios. En 1918 el catamarqueño ganaría el premio de honor por 
su poema "Oda primaveral", en un certamen literario presidido por el poeta boliviano y figura del modernismo, Ricardo Jaimes Freyre. De su viaje a Tucumán a lomo de mula para recibir el premio, dejaría una simpática estampa la revista Caras y Caretas:

Y lo mejor de los juegos florales, a lo menos lo más extraordinario, fue el viaje de 60 leguas a lomo de mula que hizo el poeta laureado para recibir la flor natural. [...] La historia del muchacho es interesante, mucho más que la crónica de los juegos... [...] Es un muchacho con esa fealdad necia y viril que hace atrayente a los hombres de carácter. No tiene ningunos de los atributos de los poetas rotulados. Ni melena, ni tez pálida, ni aire de tal. Me acordé de Horacio Quiroga en seguida. ${ }^{1}$

Un año después, en 1919, Luis Franco partiría a Buenos Aires a cumplir con el servicio militar. En 1920 comenzó sus estudios en la Facultad de Derecho de Buenos Aires. Su estadía en las aulas universitarias no duraría más que un año, pero ahí conoció a Samuel Glusberg, figura clave en sus devenires intelectuales, literarios y politicos (Tarcus, 2002).

Fue en los primeros años de la década del 20 cuando, a instancias de Glusberg, el catamarqueño empezaría a frecuentar a una referencia de primer orden del campo intelectual y literario argentino, como Leopoldo Lugones. Y, a partir de él, mantuvo, también, relación con Horacio Quiroga. A los encuentros entre Quiroga, Lugones, Glusberg y Franco, se sumaron algunos años después Ezequiel Martínez Estrada, dando lugar a la conformación de una verdadera "Hermandad" intelectual (Tarcus, 2009). Para Tarcus, fueron una serie de elementos los que amalgamaron a este quinteto de inteligencias tan broncas como dispares. Todos compartian cierta sensibilidad modernista y ciertos desplantes hispanófobos y laicistas. Este magma cultural y politico también daba lugar a otra serie de afinidades que cimentaban esta tromba intelectual, como cierto anticapitalismo romántico y una clara sensibilidad antiburguesa.

En 1920, Franco publicó su primer libro, titulado La flauta de caña (Franco, 1920), bajo el auspicio de Samuel Glusberg, a través de Ediciones Selectas de América, su primer sello editorial. El libro tenía una clara inspiración modernista y, como en la mayoría de sus poemarios, la naturaleza desbordaba en toda su exuberancia. En 1921, lanzaria otro libro, titulado Coplas. Posteriormente, debido a su frágil situación económica y a ciertos problemas de salud, debió retornar a Belén. En 1923 volvió a Buenos Aires, entró a trabajar en la Biblioteca del Conse-

1. Rodolfo Romero, "Un poeta y una aldea. La vida en Belén de Catamarca", Caras y Caretas, año XXI, n 1049, 9 de noviembre de 1918. 
jo de Educación junto a Lugones y lanzó El libro del gay vivir (Franco, 1923), que terminaría consagrándolo como poeta. El libro recibió algunas aclamaciones, entre ellas la de la poeta uruguaya Juana de Ibarbourou y también la de Leopoldo Lugones, que desde La Nación lo saludó en tono laudatorio.

La buena acogida que tuvieron sus primeros libros, el apoyo material y espiritual que prestaron los miembros de la "Hermandad", que se tradujo entre otras cosas en el sostén de Glusberg como editor y amigo y en el "espaldarazo lugoniano" (Viñas, 2007) a su obra, no sólo le permitió a Franco instalarse en Buenos Aires, sino que dinamizó su inserción en el campo intelectual. Las páginas del conservador diario La Nación se abririan a sus colaboraciones, a esto se sumaria su presencia en algunas revistas clave que animaron el convulso mundo cultural y politico de aquellos años como Babel. Revista de Arte y Crítica (1921-1929), dirigida por Glusberg. Babel fue un enorme campo de experimentación donde dejaron su huella no solo los miembros de la "Hermandad" sino también algunas de las grandes figuras intelectuales de ese momento como Arturo Cancela, Baldomero Fernández Moreno, Manuel Gálvez, Alberto Gerchunoff, Gabriela Mistral, Conrado Nalé Roxlo, Alfonsina Storni, Alfredo Brandán Caraffa, José Pedroni y Pedro Henríquez Ureña, entre tantos otros. Babel fue, sobre todo, una revista literaria construida en torno a un sentido amplio en términos estéticos y políticos. Por eso en sus páginas la poesía y la prosa tuvieron un lugar de primer orden, pero también tuvieron un espacio destacado el teatro y la música y, en menor medida, la escultura.

¿Desde cuándo comienza a participar Luis Franco en Babel? Desde el mismo inicio resalta su nombre. De hecho, de los veintinueve números que llegaron a salir de la revista, en por lo menos diez estuvo la firma de Luis Franco. De ese manojo de artículos y poemas, nos detendremos en la entrevista reproducida por esta publicación, ya que nos sirve para hacernos una idea de los nombres que articulaban la constelación intelectual del joven poeta:

-Mis lecturas poéticas -nos dice- son principalmente francesas.

-¿Cuáles son sus poetas, Franco?

-Tres -nos responde- me han causado una impresión extraordinaria y me son principalmente maestros: Whitman y Nietzsche, que hay que clasificar aparte. Y D'Annunzio, el D'Annunzio de los Laudi.

$-¿$ ¿A qué otros poetas universales gusta de leer? -inquirimos a Franco.

Y él nos dice que, armado de paciencia y coraje, trata ahora de explorar esa "selva salvaggia ed aspra e forte", que es el 
Dante, y Shakespeare, ese cosmos. [...] "Nunca me canso de leer a Samain, a Laforgue, al satánico Baudelaire y al celeste Rodenbach".2

Donde no solo supo colaborar Franco sino que figuró como uno de sus fundadores fue en Martin Fierro, una de las miticas revistas de la vanguardia argentina. En sus primeros números, aparecería una nota titulada: “¿Quién es Martin Fierro?”. La proclama había sido escrita por Evar Méndez y contenía un apartado denominado "El núcleo activo de Martin Fierro". ${ }^{3}$ Ahí aparece una ringlera de nombres, entre los que se destacan los fundadores de la revista: Leónidas Campbell, José Cairola, Oliverio Girondo, Hipólito Carambat, Ernesto Palacio, Pablo Rojas Paz, Evar Méndez y nada menos que Luis Franco.

No obstante, si bien Franco aparece entre los fundadores de la revista, sus participaciones en ella no fueron muchas. Por ejemplo, tradujo los poemas "Neere" y "Mirtin y Palemona" de Albert Samain y "El corazón de las aguas" y "De las estancias" de Jean Moréas ${ }^{4}$ e hizo una crítica favorable pero incisiva sobre los versos de Nicolás Olivari reunidos en La musa de la mala pata. ${ }^{5}$ ¿Por qué sus intervenciones fueron contadas? Podemos aventurar algunas hipótesis para intentar comprender esa distancia. Quizás el catamarqueño nunca se sintió cómodo con el modelo de intelectual que promovía la revista, con el tono jocoso -ademán característico de las vanguardias- y por momentos elitista que recorre sus páginas. Quizás, en un primer momento, adhirió a algunos de sus principios, cuando Martin Fierro iba tanteando sus formas, pero a medida que el espacio iba radicalizando y afinando su programa estético, en igual medida el poeta iba tomando distancia. A inicios de los años 20, Franco era un poeta que se estaba construyendo, que se definía por su clasicismo y su reivindicación de la naturaleza más que por una búsqueda de renovación estética como el martinfierrismo. Un elemento clave para pensar la raleada presencia de Franco en la revista es la relación que el joven poeta venía construyendo con Lugones. En la vida de Luis Franco, en la conformación de su personalidad intelectual y en su inserción en el mundo de las letras, Leopoldo Lugones jugó un rol clave. Teniendo en cuenta este dato, es posible pensar que las críticas

2. Reportaje a Luis Franco, Babel. Revista de arte y critica, segunda época, $\mathrm{n}^{\circ} 13$, julio de 1923. La entrevista original había salido en la revista Mundo Argentino, en agosto de 1922 .

3. Evar Méndez, “¿Quién es Martin Fierro?”, Martin Fierro, año I, n 12-13, octubre-noviembre de 1924.

4. Martin Fierro, año I, $\mathrm{n}^{\circ} 4$, mayo de 1924.

5. "Luis Franco. Un poeta de Buenos Aires", Martin Fierro, año IV, n 37, enero de 1927. 
que Martin Fierro dirigió a Lugones -en su intento por ajustar cuentas con la tradición- como también a Quiroga, hayan puesto al catamarqueño en un lugar incómodo. Muy posiblemente, Franco haya optado por permanecer cerca de Martin Fierro, pero sin jugar un papel central, como una forma de hacerse un lugar en el campo intelectual. Para un poeta joven y venido del interior la revista fungía como un lugar de consagración, un trampolín de futuras derivas.

En 1926 salía a escena Los hijos del Llastay, libro de relatos en el que la naturaleza ocupa el centro de la narración y se entrecruza con la cosmogonía andina. En 1927 aparecía Coplas del pueblo, publicado por Manuel Gleizer, otro de los grandes sellos editoriales de esa época. Un año después, Glusberg reúne parte de la poesía de Franco en "Los trabajos y los días". Mientras tanto, el catamarqueño colaboraria asiduamente en otro de los proyectos culturales de Glusberg, la revista La Vida Literaria. Franco tiene una presencia notoria en la revista, sobre todo colaborando con algunos de sus poemas. Pero lo interesante es que en ella hallamos una de sus primeras lecturas históricas, un rescate de Sarmiento -gesto que compartiría siempre con Lugones y Martínez Estrada-, como también una crítica furibunda a las herencias de la tradición hispánica y católica. Desde la mirada laicista de Franco, esa herencia no tenía nada para reivindicar y sólo parecía representar el incontrastable símbolo del atraso. ${ }^{6}$ Un punto alto de las colaboraciones de Franco en la revista fue en el número homenaje a José Carlos Mariátegui, después de la muerte del intelectual peruano en abril de 1930. El catamarqueño comenzaba su elegia así:

Ha muerto cuando comenzaba a ser indispensable [...] José Carlos Mariátegui, hombre doloroso y puro, cuerpo agostado y corazón caudaloso, frente de plata y voluntad de diamante, intelectual que difiere de los otros misteriosamente como el radium de los demás metales. ¡Qué fervor de justicia! ¡Qué vocación de sacrificio! ${ }^{7}$

La tónica del homenaje nos hace pensar en su mismo proceso de politización. Mariátegui no es reivindicado en tanto militante revolucionario, más bien es levantado en una dimensión individual, en la que resalta su estatura ética e intelectual, su autonomía y su personalidad poderosa antes que su capacidad de organizador, de traductor del marxismo a la

6. Luis Franco, "Sarmiento entre los yanquis", La Vida Literaria, año II, n 15, octubre de 1929.

7. Luis Franco, "Elogio hecho elegía", La Vida Literaria, año II, n² 20, mayo de 1930. 
realidad latinoamericana, donde fue capaz de echar a andar a Marx y Sorel por los escarpados caminos del mundo popular y cultural andino. Este gesto de Franco de rescatar a Mariátegui sería un elemento más, que algunos años después lo acercaria a las primeras huestes trotskistas del continente, que serian de los pocos grupos dispuestos en los años 30 a reivindicar algunos trazos del pensamiento mariateguiano.

Teniendo en cuenta estas publicaciones en algunas revistas, donde aparecen sus primeros tanteos historiográficos y políticos, cabría preguntarse qué relación comenzó a construir el poeta con la política durante la década de 1920. En estos años de formación, Franco fue lentamente rozando la política en sentido amplio. Era un joven que brillaba por su inconformismo militante, su laicismo, su hondo sentido de libertad. De alguna manera sus brumosas intuiciones políticas y sociales se plasmaron en su primer ensayo América inicial (Franco, 1931), texto recubierto por cierto vitalismo, pletórico de nociones espiritualistas que conviven con pizcas de aristocratismo, que habian saturado algunos discursos desde la primera década del siglo XX a través del "arielismo" y de ciertos tópicos del reformismo. Como bien apunta Campione pensando en su proceso de politización: "En su juventud no tiene una adscripción política definida, su afán contestatario tiene que ver con su lectura de Whitman o Nietzsche, no todavía con la tradición política de izquierda" (Campione, 2008, p. 11).

\section{La responsabilidad de los intelectuales: la politización de un poeta pagano}

El proceso de politización de Luis Franco fue levando en los años 20. Las primeras nociones en torno al compromiso político del intelectual le venían a Franco de la tradición modernista. Poeta empapado en el magma del tardomodernismo, ahí pudo cotejar la tentación de algunas de sus figuras de convertirse en baluartes éticos e ideológicos de sus sociedades. También la vida y la obra de su admirado Walt Whitman fueron claves para que Luis Franco fuera cincelando ciertas nociones de las responsabilidades del intelectual. Sin embargo, la politización de Franco, como la de tantos otros intelectuales, tomaria forma definitiva en el devenir de la década del 30, alimentada por la marca que fueron dejando una serie de fenómenos y acontecimientos, tanto en el plano local como internacional. El derrocamiento del gobierno radical con el golpe de estado de 1930 y la apertura de un ciclo político marcado por la represión y el fraude, que volvían todavía más asfixiante el clima social y político del país, atravesó la sensibilidad del poeta. A un caldeado marco nacional, se sumaban los violentos ramalazos del contexto internacional: la crisis provocada por la "Gran Guerra" y los ecos de la revolución de octubre vibraban en el mundo. Si en el transcurrir de los años 20 se 
había dado la consolidación del fascismo, la década de 1930 marcaría un punto de no retorno, con la llegada al poder del nazismo y el inicio de la Guerra Civil Española. Como remarca María Teresa Gramuglio, estos hechos, más el devenir de la vida política nacional, fueron cimentando la pregunta en torno a la responsabilidad del intelectual, afirmando la imperiosa necesidad de la toma de posición (Gramuglio, 2013).

¿Qué hechos nos permiten ver de manera nítida, en su singladura, el encuentro de Franco con la política a lo largo de los años 30? Son varias las cuestiones que balizan ese tránsito: su retorno a Belén a inicios de los 30 y su corrimiento de ciertos ámbitos intelectuales, su adscripción definitiva al marxismo, sus diálogos con las primeras huestes trotskistas, sus discusiones con Martinez Estrada en torno al rol del intelectual, el inicio de sus indagaciones históricas y su inmersión en el ensayismo como así también el impacto de la Guerra Civil Española en su obra y su conciencia.

En los primeros años de la década del 30, Franco retornaría a Catamarca, en un largo retiro que se extenderia hasta principios de 1950. Esta especie de ostracismo autoimpuesto fue tanto una apuesta vital como un intento de descorrerse de ciertos ámbitos intelectuales. Como parte de esa apuesta, Franco abandonaria, por cuestiones políticas, algunos espacios de consagración, como eran sus colaboraciones en el diario La Nación y en noviembre de 1936 también rechazaria la invitación de la SADE para participar de su primer congreso. Instalado en Belén, dividido entre las faenas agrarias y sus lecturas, Luis Franco se sumergiría con avidez a deglutir los clásicos del marxismo. Desbrozaria a Marx y Engels, a Lenin y Trotsky. El poeta en estos años fue construyendo una singular apropiación del marxismo, que no estuvo mediada por partido o figura tutelar alguna y que fue deviniendo en un marxismo anclado en una fuerte idea de libertad -pendulando en esa tensión siempre irresuelta entre individuo y comunidad- y atravesado por una rabiosa prédica antiestatista. En el marxismo que fue labrando, los clásicos de esta tradición eran pensados y cribados a partir de las lecturas de Nietzsche y de Henry David Thoreau, personajes claves en el catamarqueño para abordar la política como los así llamados "deberes" del intelectual.

A la par que Franco se sumergía en el marxismo y en el contexto del proceso de reinvención de la figura del intelectual al que hicimos referencia antes, apareció la posibilidad, en 1933, de construir una revista político-cultural junto a una troupe variada, heteróclita de militantes e intelectuales, entre los que convivian tanto Glusberg y Martínez Estrada como algunas figuras vinculadas a los primeros balbuceos del trotskismo. Más allá del naufragio del proyecto por distintos motivos, en esos intercambios, Franco empezaria a tejer delicados vínculos con los 
primeros grupos trotskistas que empezaban a florecer en la Argentina desde fines de 1920 (Coggiola, 2006; Tarcus, 2009; Rojo, 2012; Camarero, 2020). Así empezaría a vincularse con algunas figuras señeras de esta tradición como lo fueron Héctor Raurich, Carlos Liachovitzky y, posteriormente, Antonio Gallo. ¿Por qué Franco se acercó a los pequeños círculos trotskistas? Claramente su relación con Glusberg fue clave en este acercamiento. Además, el trotskismo convidaba al escritor con un marxismo mucho más audaz en términos políticos y teóricos que el que levantaba el Partido Comunista argentino. Por otra parte, si algo caracterizó a estos núcleos de militantes desde sus inicios sería la vocación no sólo por establecer contactos con el mundo obrero sino también por desarrollar una amplia tarea intelectual que pudiera convivir con los gajes de la militancia cotidiana. Fue a partir del vínculo con estas figuras y con algunos de sus debates que Franco empezó a hermanar su vida y su obra en la estela dejada por el "profeta desterrado". ¿Pero en qué se basaba esta relación? Sus vínculos con estos grupos trotskistas radicaban en una afinidad política, pero nunca adquirieron un carácter orgánico. La relación de Franco con el trotskismo durante la década del 30 fue una relación de contacto, epistolar, triangulada en muchos casos por Glusberg y alimentada a través de proyectos de revistas, encuentros y pequeños viajes. Otros elementos que contribuyeron a este tipo de relación fueron, por un lado, el aislamiento de Franco, que estaba radicado en la lejana Belén, y, por el otro, la fragmentación política del trotskismo en los años 30, que dificultaba la incorporación de algunas figuras a este universo militante.

El proyecto de la revista no terminaría de coagular y sería Ezequiel Martínez Estrada el primero en desistir de la idea, lo cual abriria una filosa polémica entre Martínez Estrada y Franco. ¿Cuál era el nervio del altercado? A partir de las cartas rescatadas por Tarcus, podemos ver que el debate giraba en torno al rol del intelectual, y de ahí florecen otras puntas de la discusión como el vínculo entre la política y la intelligentsia, la autonomía del conocimiento con respecto a la realidad. En una misiva, Martínez Estrada le trazaría un sombrío cuadro de situación a Glusberg:

Recuerdo constantemente el grupo de buenos amigos meltianos ${ }^{8}$ y cada vez son en mí más hondas las convicciones y más desalentadoras las conclusiones a que llego con respecto a lo que se puede hacer. Parece increíble que todo esto sea un

8. Según Tarcus (2009), la sigla MELT hace referencia a "Movimiento Emancipador por la Lucha y el Trabajo" o "Mutualidad de Estudios, Lucha y Trabajo". También Tarcus asocia las siglas a Marx, Engels, Lenin y Trotsky. Esos espacios fueron más bien proyectos que nunca llegaron a cuajar en una organización determinada. 
pedazo de pulpa agusanada; hay que tocarlo para advertir que quizá no hay nada que hacer. ${ }^{9}$

De a poco, Martínez Estrada empezaría a radicarse en una geografía inhóspita, una tierra baldía a la que pocos ansían llegar: el país de los agoreros. La "amargura metódica" de Estrada no se detiene en el presente, sino que impugna también la misma idea de futuro, lo que constituía un tiro por elevación a la noción de "progreso" (Ferrer, 2014). A contrapelo, Franco, inmerso en su proceso de politización, cifraría su crítica del presente en un optimismo alimentado por la posibilidad de la revolución. De ahí que viera en la mirada pesimista de su antiguo cofrade, una actitud estéril, una apología de la nada. "Lo escéptico es lo prescindente, es decir, la esterilidad del asexuado" le diría en una carta a Glusberg, en medio del fragor de la polémica. A diferencia de Martínez Estrada, Franco no pretendia ser el heraldo de lo infausto, sino uno de los pregoneros de la revolución. Aunque sea con un desplante ético, el intelectual debía pronunciarse, enrolarse en los bandos en pugna. En la mirada del catamarqueño, era deber de la intelligentsia denunciar los modales prostibularios de la sociedad, ser la voz discordante en el reino del murmullo monocorde -gesto que compartió hasta el final con Martínez Estrada-. En esta apologia del posicionamiento que hacia Franco, Martínez Estrada no veía más que un juego masturbatorio, una lealtad sostenida con Onán. Por el contrario, Franco diria:

mas yo sigo creyendo que la sola definición de nuestra actitud, en la tierra de los Gálvez y Capdevilas, tiene un valor moral considerable (no proponiéndonos ser los Lenin y Trotsky de nuestra futura revolución) nuestro papel de agitadores en el terreno ideológico, de perturbadores de la conciencia estólida de nuestros políticos, sociólogos e historiadores a sueldo, nuestra función de piqueta y espuela, en fin, no será absolutamente despreciable. ${ }^{10}$

Si la polémica con su viejo cofrade es parte de su politización, en la misma línea se puede leer el inicio de sus incursiones en la historia. Luis Franco empezaría a bucear en el pasado, buscando alli -como tantos otros escritores e intelectuales en esa época- algunas claves que le permitieran entender la crisis de la Argentina y el mundo (Acha, 2009a; Cattaruzza y Eujanian, 2003). Se fue acerando en él la convicción de

9. Carta de Ezequiel Martínez Estrada a Samuel Glusberg, 31 de diciembre de 1933 (cit. por Tarcus, 2009, pp. 100-101.)

10. Carta de Franco a Samuel Glusberg, c. 1935 (cit. por Tarcus, 2009, pp. 225-226). 
que cualquier intervención política debía estar anclada en una determinada lectura de la historia. Como remarcó Sarlo, la historia atravesó en esos años muchos de los discursos narrativos y pasó a ser una preocupación central del mundo de los escritores (Sarlo, 2020, p. 27). Las primeras lecturas históricas de Franco saldrian a la luz en Trapalanda. Un colectivo porteño (1932-1935), otra de las revistas fogoneadas por Glusberg. Desde esta publicación, tanto Franco como Martínez Estrada fustigarian con fuerza el panteón histórico nacional (Ferrer, 2014). En el primer número de la revista, Franco empezaría el carneo histórico de la figura de Rosas. La vocación del poeta por auscultar esta figura se daba en el marco de un momento intelectual en el que comenzaban a ganar terreno algunas lecturas de la historia, particularmente la revisionista, que intentaban reivindicar la figura del "Restaurador". Cuando interpretó al rosismo, Luis Franco intentó descorrerse del gastado encasque de la teratología, a la vez de lo que él entendia como la falsa dicotomía entre "libertad y tiranía". Trató de situar a Rosas en un marco social y económico determinado, presentándolo como un "gaucho-burgués". ${ }^{11}$ Si bien Franco intentó saltarse el casillero del monstruo para explicar a Rosas -por momentos lo logra-, no dejó de denunciar la violencia del régimen y los hitos de la mazorca; para este poeta el "rosismo" significaba un retroceso con respecto a los sucesos de mayo de 1810, un cierto "retorno" de las herencias coloniales. ${ }^{12}$

Un hito en su producción lo constituyó la aparición de El General Paz y los dos caudillajes (1933), primer libro de su cosecha histórica. Viñas diría sobre este ensayo que se trata de un "trabajo que si en sus procedimientos aún aparece impregnado por el "biografismo retórico" desplegado por Lugones en su Sarmiento, en la franja ideológica se sitúa antagónicamente respecto del Rosas de Ibarguren y, sobre todo, del revisionismo de derecha tan copioso a lo largo de las décadas del 30 y 40" (Viñas, 2007, p. 7). En este primer bosquejo histórico, si bien el marxismo no reverbera plenamente en sus páginas, Franco esboza ciertas muecas interpretativas que lo seguirán acompañando a lo largo de toda su vida. En el ensayo abordó, entre tantas cosas, el fenómeno del caudillaje, fenómeno clave para entender los devenires políticos del siglo XIX. Pero también se detuvo a pensar los sucesos de mayo de 1810. La "Revolución de mayo" antes que una "gesta por la libertad"

11. Luis Franco, "Rosas, gaucho burgués", Trapalanda. Un colectivo porteño, $\mathrm{n}^{\circ} 1$, octubre de 1932. Edición facsimilar de la Biblioteca Nacional.

12. De los siete números que salieron de Trapalanda, Franco colaboró en dos más y siempre lo hizo desde el ensayismo histórico: "Los dos caudillajes" ( $n^{\circ} 4$, julio-agosto de 1933) e "Historia argentina" ( $n^{\circ} 6$, noviembre-diciembre de 1933). 
era presentada como un movimiento de las clases dominantes tendiente a liberarse del fórceps colonial, para poder comerciar libremente con Inglaterra. Los "hechos de mayo" para el poeta eran un fenómeno eminentemente porteño, que en sus inicios se daba de espalda al resto del territorio. Lo interesante también es que esta mirada de la revolución sería recuperada y profundizada por algunas franjas de la historiografia trotskista, particularmente la desarrollada por Milciades Peña (Acha, 2009b; Camarero, 2013; Tarcus, 1996). Al igual que otros en su época, Franco comenzaria su trabajo de relectura de la historia empujado por la idea de que en el fondo de los tiempos aguardaba una "historia verdadera" que debía ser deslastrada para que ascendiera a la superficie y pudiera ser aquilatada por la sociedad toda. Así, la tarea del historiador se insinuaba en Franco como una tarea de zapa; un trabajo que consistía en demoler a preguntas el orgulloso inventario de gestas y conquistas que reivindicaba la nación.

En este extendido proceso de politización, el inicio de la Guerra Civil Española fue un hecho fundamental. Gramuglio insiste en que la lucha en España "se convirtió en un verdadero parteaguas para la redistribución de posiciones en el campo literario" (Gramuglio, 2013: 242). Además, como remarca Saítta, en esta década se da un proceso de "internacionalización" del compromiso político de los intelectuales. De alguna manera la Guerra Civil Española, sintetizaba este proceso (Saítta, 2001). Franco siguió detenidamente cada acontecimiento de la Guerra Civil, como la atestiguan sus cartas con Glusberg. Si al principio adhirió al bando republicano sin miramientos, con el transcurrir de los años fue puliendo su mirada, volviéndola más nítida en lo que hace a los acontecimientos políticos. Sus análisis de España se plasmaron en su libro Biografía de la guerra, trabajo amasado en la soledad de Belén a medida que se desovillaban los acontecimientos. Para el poeta la derrota se debía, entre tantas cosas, a la incapacidad y a la falta de voluntad del gobierno republicano por radicalizar el proceso e invertir las relaciones de fuerza entre la clase obrera y la burguesía. En sintonía con esa lectura, Franco sería un crítico acérrimo de la política de los frentes populares. Diria:

el Frente Popular, con la colaboración stalinista y con todas las incongruencias y menguas que provienen de su falla básica: la renuncia del proletariado a su política de clase, es decir, revolucionaria, en homenaje a su alianza con la burguesía pequeña y media, en una época en que la polarización aguda de las fuerzas sociales sólo deja en pie dos verdaderos frentes de lucha [...] la burguesía fascista o fascistizante y el proletariado revolucionario. (Franco, 1941a, pp. 125-126). 
A la vez que arremetía contra estos aspectos, se encarnizaba en su crítica con la política soviética y particularmente contra el stalinismo. Para Franco el papel de la URSS en España había sido abiertamente contrarrevolucionario (idem, p. 133). Los sucesos de España marcarían un punto clave en el proceso de politización de Luis Franco, ya que a partir de ahí se volvió absoluta su desconfianza para cualquier salida de tipo reformista como a la vez se fue sellando su lento acercamiento a algunas líneas políticas del trotskismo.

\section{Arte y política: una díada compleja}

A medida que Franco avanzaba en su proceso de politización, y en el marco de los años 30, fue haciéndose más persistente en su reflexión el complejo vínculo entre arte y política. En medio de ese proceso de reinvención de su propia figura como poeta y en un contexto atravesado por grandes apuestas politicas, Luis Franco fue enhebrando una serie de preguntas vitales: ¿Qué papel le correspondia al artista en ese contexto? ¿Qué debía expresar su poesía para estar a tono con la hora dramática de sus dias? Una serie de intervenciones de Franco en algunas revistas chilenas nos sirven para adentrarnos en el tema.

En 1935 Glusberg se radicó definitivamente en Chile y a instancias suyas Franco viajaría a ese país a dictar unas conferencias y participaría de los debates que se venian dando en algunos medios intelectuales. Glusberg volcó su calidad de editor en varios espacios, entre ellos la revista SECH (1936-1939), publicación de la Sociedad de Escritores de Chile, cuya acta de fundación data de 1932 (Ferreti y Fuentes, 2015 y Hernández Toledo, 2020). SECH llegó a publicar nueve números y reunió a un amplio espectro de la intelectualidad chilena, entre los que se destacan Manuel Rojas, Ernesto Montenegro, Januario Espinoza y Pablo Neruda. Si algo palpita en $\mathrm{SECH}$ es el vínculo entre el escritor y la politica. En el primer número de $S E C H$ aparece una entrevista a Franco, en el marco de una visita del catamarqueño al país vecino en 1936. A Franco se le preguntará por su arte y cómo se articulan la política y la creación:

-Entiendo que su vocación y labor son principalmente poéticas.

-Es verdad; mas desde algún tiempo mi preocupación por el problema social en su conjunto, es absorbente. Y en esto no hay contradicción. Creo que la más vieja falla del arte está en considerarlo como un ornato o un pasatiempo. [...] Recuerde Ud. aquello de Sarmiento: "El arte es la realización del hombre". La intuición le permitió entrever a Sarmiento que el arte no era 
ni una manifestación de lo Absoluto como creen los místicos, ni un deporte o sonajero como piensan algunos filósofos.

- ¿Cree Ud. en la posibilidad de un arte nuevo?

-Pienso que el arte tiene que ser irrefragablemente expresión de sentimientos universales - "cosa de fundamento", dice Martin Fierro- o sea de aquellos en que comulgan todos los hombres. El arte de las minorias selectas o deshumanizadas, digamos, el arte contemporáneo, se debate en el vacío. En una sociedad erigida sobre la explotación y la servidumbre cada vez más evidente de la casi totalidad de los hombres, el arte estaba condenando a eso, a volverse un elegante artificio. [...] Una nueva experiencia vital, es lo único que puede engendrar un arte nuevo, verdadero, es decir, para todos los hombres [...] Así, pues, un arte nuevo exige la renovación de todo el sistema social. ${ }^{13}$

El que va enhebrando las respuestas a estas preguntas es ya un marxista convencido, un escritor que empieza a ver en el cruce con la política la necesidad vital de un nuevo modelo de intelectual que reclama la época, un poeta que se conmueve con las peripecias políticas del trotskismo. A medida que la entrevista avanza, cobra peso la pregunta en torno al rol de los intelectuales. En el caso de Luis Franco, el intelectual aparecía como aquel que devela, muestra, escruta los fondos de la sociedad para "romper un poco el grotesco biombo que oculta nuestra sublevante realidad". En su retina el intelectual crítico es quien asume en parte la tarea de urticar la sensibilidad plomiza que recubre y estructura el sentido común de la sociedad. La entrevista prosigue levantando su apuesta política: “¿Cuál es el problema social más importante de la Argentina?”. Después de un mínimo rodeo Franco respondia:

El capitalismo que ha roto todas las fronteras y gobierna todos los gobiernos, es internacional por excelencia. De ahí que la redención de la miseria nacional no pueda ser asunto puramente nacional.

Dicho esto volvería a sentar posición en torno al problema de los intelectuales:

o el escritor está con la revolución, que encarna el espíritu viviente, o está en contra, esto es, con las formas momificadas, y entonces su obra es estéril, cualquiera sea el brillo de

13. Luis Franco, "Una conversación con Luis Franco", Revista SECH, Santiago de Chile, año $1, \mathrm{n}^{\circ} 1$, julio de 1936, p. 31. 
su ingenio o su técnica (...) la causa emancipadora precisa de hombres integramente emancipados del fardo milenario de prejuicios que pesan sobre la gente. Entre los más capaces de serlo está el escritor, acaso, entre todos, el más llamado a dar alerta de lo nuevo en un mundo encarcelado e inerte en que toda creación supone revolución. ${ }^{14}$

La discusión en torno a arte y política proseguirá en otro escenario de la intelectualidad chilena, la revista Anales de la Universidad de Chile. En su ensayo, Franco partía de un diagnóstico: la vida del hombre moderno se muestra superficial, falta de sentido. Son mujeres y hombres aislados, despojados de sentido de comunidad. A este sentimiento de orfandad tributan la progresiva mecanización de la vida, la creciente alienación moderna, la pérdida de voluntad creadora, la reificación de la vida toda. Aseveraría el catamarqueño:

El camino del hombre occidental desde el Renacimiento hasta hoy, camino jalonado de espléndidas hazañas, ha sido no obstante, el de una disgregación progresiva; el hombre separa su cuerpo de su alma, separa su yo de los otros y del mundo, se convierte en una oculta voluntad de aislamiento y esterilidad, bajo su ostensible voluntad de riqueza, de poderío material, de progreso. El agente y símbolo de esta verdadera edad de fierro que tiene por ideal el dinero, es la máquina, que de servidora del hombre, se convierte en ídolo que él alimenta con su carne y espíritu. ${ }^{15}$

En la óptica de Franco nos hallábamos ante una humanidad alienada, que encontraba una de sus expresiones en el campo del arte. El arte se volvía nihilista, clamaba por divorciarse de lo social, buscaba ser cósmico porque odiaba los misterios inexplicables de la tierra. Diría el poeta: "Pero este desprecio de la realidad es sólo la máscara de una enfermedad antiquísima: el reniego de la vida". ${ }^{16}$ ¿Quiénes eran los representantes de este arte decadente? De acuerdo a Franco podríamos incluir entre ellos a Paul Valéry, Jean Cocteau, Paul Morand hasta Marcel Proust, a quien caracterizará como "un asmático siempre yacente que segrega una prodigiosa literatura para invertebrados". En todos ellos, cree constatar un arte de evasión, un arte que no puede mirar al

14. Luis Franco, "El escritor y el cuadrante", Revista SECH, Santiago de Chile, año $1, \mathrm{n}^{\circ}$ 6, octubre de 1937, pp. 16-17.

15. Luis Franco, "Arte y realidad", Anales de la Universidad de Chile, Santiago de Chile, $\mathrm{n}^{\circ} 21$, enero-marzo de 1936, p. 66.

16. Ídem, p. 67. 
futuro, que da la espalda a los grandes desgarros sociales. Se trataria, entonces, de un arte en fuga, un arte que deserta de la vida porque es incapaz de transformar cualquier aspecto de la realidad.

Tampoco el catamarqueño vería en el surrealismo una apuesta totalmente superadora, la posibilidad de fundir en otro cáliz arte y realidad, compromiso político y contemplación. El surrealismo era una protesta contra el mundo, un claro acto de rebeldía. Pero esos pataleos, esa histriónica defensa de la fantasía como una de las formas de arrancar al mundo de los embrujos de la fetichización, para Luis Franco no eran más que estertores de rebeldía, rabietas grupales que no podrán cantar los sentimientos de la nueva vida. "El rechazo de lo convencional, en efecto -diría el poeta-, suele pasar apenas de una declamación o una coqueteria: la ideología y la emotividad del rebelde son ortodoxas en el fondo: su entraña permanece más o menos intacta". ${ }^{17}$ Lo que Franco exigía en su querella contra el surrealismo era el paso del rebelde al revolucionario, de la crítica al orden decadente a la comunión con la plebe en una praxis liberadora; desplazamiento político que Franco estuvo lejos de terminar de modelar en su propia vida, en sus propias peripecias como intelectual de izquierda. Más que un intelectual orgánico, Luis Franco prefirió seguir sosteniendo siempre una posición autónoma, sin que esto le impidiera acompañar algunos proyectos intelectuales y políticos del trotskismo morenista ${ }^{18}$ hasta el final de su vida. ${ }^{19}$

A diferencia de otros marxistas contemporáneos -como Raúl González Tuñón y Cayetano Córdova Iturburu (Saítta, 2005)- que, hasta la

\section{7. Ídem, p. 69.}

18. Nahuel Moreno fue una figura clave del trotskismo argentino y latinoamericano. A partir de la década de 1940, y hasta su muerte en 1987, animó la creación de diferentes agrupamientos políticos (entre los cuales se encuentran el Grupo Obrero Marxista, el Partido Obrero Revolucionario, Palabra Obrera, el PRT, el Partido Socialista de los Trabajadores y el Movimiento al Socialismo), convirtiéndose su nombre en referencia de una determinada corriente al interior el trotskismo argentino.

19. Una de las vías de contacto de Franco con la corriente morenista fue a partir de la relación que sostuvo, desde principios de los años 50, con el historiador y militante trotskista Milciades Peña. Esto hizo que la vinculación con el morenismo fuese bastante particular, sobre todo teniendo en cuenta la tensión permanente que caracterizó la relación entre Peña y el partido. Sin embargo, Franco acompañó varias instancias partidarias, desde el intento de la revista Estrategia, publicación que llegó a tener 3 números, desde septiembre de 1957 hasta junio de 1958, y de la que participaron figuras como Rodolfo Puiggrós, Silvio Frondizi, Eugenio Werden, Enrique Rivera y Carlos Astrada. Además, fue uno de los impulsores de la campaña, realizada a mediados de los 60, por la libertad del dirigente campesino y militante trotskista peruano Hugo Blanco encarcelado en su país de origen. También en 1982 Luis Franco acompañó la constitución del Movimiento al Socialismo (MAS). 
mitad de la década de $1930,{ }^{20}$ vieron en el surrealismo una novedosa forma de concebir la díada arte y realidad, el poeta pagano nunca sembró esperanzas sobre ese lábil territorio que empezaba a labrar la vanguardia francesa. Como plantea Michael Löwy para algunos marxistas, el surrealismo fue considerado una radical apuesta político-estética, "un auténtico movimiento de rebelión del espíritu y una tentativa eminentemente subversiva de reencantamiento del mundo" (Löwy, 2006, p. 9). Franco, en cambio, no se sintió nunca plenamente convocado por el accionar de las vanguardias. Este ensayista compartía algunos diagnósticos con el surrealismo en torno a la alienación, a los efectos devastadores de la técnica en las sociedades modernas. Sin embargo, para Franco, la posibilidad de reencantar la vida, de pensar otra relación entre los seres humanos y la naturaleza, hallaba su único antídoto en la revolución política. ${ }^{21}$ Más allá de que Luis Franco nunca dejaría de anotar varios puntos en el debe del accionar político de los surrealistas, también sabría reconocerles ciertos afanes políticos, ciertos ademanes de ruptura. Los surrealistas no rehuian de la política, no tenían la pretensión de poner al arte a resguardo de las rudas pasiones humanas. ${ }^{22}$

Para Luis Franco, el arte nuevo no podría surgir de las entrañas de la vieja sociedad capitalista, sino que se erigiría sobre sus ruinas. Sólo a una humanidad liberada, le correspondería un nuevo sentido del arte y la creación. Ese arte que Franco imaginaba seria un arte de mayorias, un arte viviente, que habría sabido jubilar los miedos y dogmas de la sociedad de otrora. El arte de la nueva era no sería pasatiempo, sino expresión profunda de los grandes desgarros sociales y anhelos que sajarian a las mujeres y hombres de ese tiempo. No sería un arte

20. Es necesario tener en cuenta que la poesía de estos poetas en relación al surrealismo se fue modificando al compás de las reformulaciones estéticas realizadas por el comunismo a nivel internacional. A medida que se reivindicaba el realismo como expresión del arte revolucionario, en igual medida se modificó el juicio sobre las posibilidades revolucionarias del surrealismo.

21. Es necesario tener en cuenta que los surrealistas no renegaban de la idea de la revolución política y social, sino que también la aunaban a su propuesta de revolución estética y espiritual, que transformase por completo la vida humana.

22. En 1938 se publicaba el "Manifiesto por un arte revolucionario independiente" texto escrito por André Breton y León Trotski, al cual también suscribiría el pintor Diego Rivera. No sabemos si Franco tuvo contacto con este texto y si le permitió cierta relectura del surrealismo. Es posible que haya tenido conocimiento de él gracias a Samuel Glusberg, quien fue uno de los responsables de su circulación en Chile. Hay algunos puntos del manifiesto a los que Franco podría haber suscripto, entre ellos merecería destacarse la idea de libertad en el arte, la defensa de un arte revolucionario y la noción de que un nuevo sentido del arte sólo podría brotar de un nuevo tipo de sociedad. Véase Tarcus (2019). 
al servicio de la religión o de la moral. Sino una creación autónoma porque expresaría

Otra respuesta al misterio, otra intuición del mundo. Significa una experiencia de la realidad, tan válida como el conocimiento científico o el religioso. El arte que transporta al hombre de lo personal a lo universal significa una de las comuniones del hombre con sus semejantes y con el universo. [...] El arte, es pues, ingrediente capital de la civilización, elemento indispensable de la humanidad en su camino hacia una forma de vida cada vez más elevada. ${ }^{23}$

Ahora bien, si el catamarqueño fue sumamente crítico con las visiones de un arte escindido de lo social y lo político así como con la apuesta surrealista, tampoco vio en el "realismo socialista" la solución al problema de la vinculación entre arte y política. Así como tampoco fincó ninguna esperanza en un arte rebajado a convertirse en mero vehículo de consignas políticas. Si el artista convertía su arte en propaganda, para Franco, se traicionaba a sí mismo y a su creación. Luis Franco anotaría pensando en esta discusión: "Si la literatura quiere ser revolucionariamente fecunda, ha de ser arte literario y no propaganda". ${ }^{24}$

Estas reflexiones en torno a la relación entre arte y politica, ¿hallaron rápidamente una nueva forma en su poética? Siguiendo su producción durante estos años, podemos ver que no fue sino hasta mediados de la década de 1930 que empezó a establecerse un cruce más directo entre su poética y su acercamiento a la política. Esa incorporación de lo político fue un proceso lento, paulatino. La asunción del marxismo, su politización, no se tradujo linealmente en una renovación temática ni en la aparición de nuevas formas en su arte. Si pensamos en el poemario Nocturnos (Franco, 1932), es imposible hallar en éste trazos de su proceso de politización. Más bien, Franco se volcaría allí a desplegar un tono intimista, por momentos melancólico, en detrimento del panteísmo como argamasa de su constelación poética. Sin embargo, a partir de mediados de esta década, el cruce entre arte y política comenzó a plasmarse en algunos poemas como "Coplas del meditabundo", ${ }^{25}$ publicado en la revista Flecha-dirigida por Deodoro Roca- o su poema

23. Luis Franco, "Arte y realidad", Anales de la Universidad de Chile, Santiago de Chile, $\mathrm{n}^{\circ} 21$, enero-marzo de 1936, p. 69.

24. Luis Franco, "Autonomía del artista", Flecha. Por la paz y la libertad de América, Córdoba, $\mathrm{n}^{\circ} 17$, agosto de 1936.

25. Luis Franco, "Coplas del meditabundo", Flecha. Por la paz y la libertad de América, Córdoba, $\mathrm{n}^{\circ} 17$, agosto de 1936. 
“Trotsky" publicado en 1937 en Repertorio Americano, la revista dirigida por Joaquín García Monge y que, posteriormente retocado, volveria a ser publicado en Babel. Revista de revistas. ${ }^{26} \mathrm{El}$ poemario Suma, de 1938, contenía también algunos poemas, en el último tramo del libro, que daban cuenta de un contenido más explícitamente político, como "Madre revolución" (Franco, 1938). Así, de manera sutil, siempre cuidada, Franco iba entrelazando su búsqueda politica con su apuesta poética.

\section{Consideraciones finales}

La singladura intelectual y política de Luis Franco entre las décadas del 20 y el 30 nos sirve para seguir desentrañando aspectos y procesos del complejo mundo intelectual de la Argentina de ese período. Franco hizo un lento proceso de politización, amparado por el clima intelectual de los años 20, que no había exigido definiciones tan tajantes, habilitando zonas de intercambios entre distintos polos del campo intelectual, que serian imposibles de ser sostenidos en el clima de creciente radicalización y de necesaria toma de posición que marcó a los años 30 . Contra esas imágenes que ha discutido Gramuglio de la década de 1930 como un momento de contracción y opacidad del campo intelectual, esta década significó para Franco y otros intelectuales un momento pletórico de proyectos e intervenciones. Alejado de cualquier forma de apatía política o abulia intelectual, el catamarqueño produciría en el terreno de la poesia, a la vez que haria su desembarco en las costas del ensayo. En ese sentido, podrían resaltarse algunos desplazamientos en la producción de Franco durante esos años. En primer lugar, en los 30 la poesía comenzaba a ocupar un espacio más relegado dentro de su obra, ganando cada vez mayor peso sus ensayos históricos y políticos, muchos de ellos madurados y bosquejados en los años 30 pero publicados a inicios de los 40, como su Biografia de la guerra, sus ensayos sobre Walt Whitman (Franco, 1941b y 1945a) y su lectura histórica del rosismo, resumida en El otro Rosas (Franco, 1945b). En segundo lugar, en el transcurso de esta década, se fue dando un lento proceso de entrecruzamiento entre la política y el arte al interior de sus textos. Esto se plasmó -como antes dijimos- tanto en sus reflexiones en torno a la función del arte y al rol del artista, como en la emergencia de ciertas temáticas y referencias politicas que comenzaron a estructurar parte de su poética. Por último, su filiación con el marxismo, que acompañó sus indagaciones en torno a la relación entre arte y política, no lo llevó a recostarse sobre ninguna de las corrientes artísticas sobre las que se

26. Luis Franco, "Vida y muerte de Trotsky", Babel. Revista de revistas, Santiago de Chile, $\mathrm{n}^{\circ} 15$, enero-abril de 1941. 
dirimieron, en esos años, la mayor parte de los artistas e intelectuales de izquierdas, como el surrealismo o el realismo socialista. Podriamos preguntarnos, entonces, hasta qué punto esa no adscripción a las discusiones en pugna no fue una de las causas de cierta incomodidad de Luis Franco en el mundo literario y otras de las tantas causas que contribuyeron a su paulatino descentramiento.

Restan pensar múltiples aspectos de la trayectoria intelectual y política de Luis Franco. Este fecundo poeta y ensayista, atravesó, casi integramente, todo el siglo XX. No hubo fenómeno político o cultural de su tiempo que le fuera totalmente ajeno. Como otras figuras de izquierda, sintió como un mazazo la irrupción del peronismo e intentó moldear algunas explicaciones que dieran cuenta de este fenómeno que parecía hacer trastabillar las ilusiones politicas de las izquierdas. Durante la década de 1950 publicaría algunos de sus grandes ensayos, que abarcarian no sólo la historia patria sino también algunas de sus figuras intelectuales más admiradas como Sarmiento y Hudson. Recuperar la trayectoria de Luis Franco es una forma de enmallar en el relato histórico una variedad de apuestas que van desde duelos intelectuales y connatos políticos, a sueños de revistas y libros desmochados como anhelos de revoluciones que parecen anidar temblorosos en oscuros socavones de la memoria. Esta trayectoria es la historia de ciertas amistades, de ciertos libros que quisieron sacudir el panteón de los dioses nacionales, de algunos desafios que vinieron a alborotar el debate intelectual, de pequeñas epopeyas politicas e interpretativas que tuvieron a Luis Franco como un personaje central.

\section{Bibliografía}

Acha, O. (2009a). Historia critica de la historiografia argentina. Vol. 1: Las izquierdas en el siglo XX. Prometeo.

Acha, O. (2009b). Nacionalismo y progreso histórico en Milcíades Peña. En http://www.herramienta.com.ar/revista-herramienta-n-23/nacionalismo-y-progreso-historico-en-milciades-pena.

Camarero, H. (2013). El período formativo de un intelectual: Milcíades Peña y el trotskismo en la década de 1940-1950. Archivos de Historia del Movimiento Obrero y la Izquierda, II, 3, pp. 9-33.

Camarero, H. (2020). Contra la corriente. La Oposición de Izquierda en Argentina, 1929-1933. Archivos de Historia del Movimiento Obrero y la Izquierda, IX, 17, pp. 15-38.

Campione, D. (2008). Estudio Preliminar. En L. Franco, La Pampa habla. Ediciones de la Biblioteca Nacional.

Cattaruzza, A. y Eujanian, A. (2003). Políticas de la historia. Argentina 18601960. Alianza. 
Coggiola, O. (2006). Historia del trotskismo en Argentina y América Latina. Razón y Revolución.

Correas, B. (1962). Luis Franco. Ediciones Culturales Argentinas.

Ferrer, C. (2014). La amargura metódica. Vida y obra de Ezequiel Martínez Estrada. Sudamericana.

Ferreti, P. y Fuentes, L. (2015). Los proyectos culturales de Samuel Glusberg. Aportes a la historia de la edición independiente en la primera mitad del siglo XX latinoamericano. Andamios, 12, 29, pp. 183-206.

Franco, L. (1920). La flauta de caña. Selectas de América.

Franco, L. (1923). El libro del gay vivir. Babel.

Franco, L. (1931). América inicial. Arco, parábolas y otras curvas. Babel.

Franco, L. (1932). Nocturnos. Babel.

Franco, L. (1938). Suma. Perseo.

Franco, L. (1941a). Biografia de la guerra. Perseo.

Franco, L. (1941b). Walt Whitman, el mayor demócrata que el mundo ha visto. Perseo.

Franco, L. (1945a). Walt Whitman, Americalee.

Franco, L. (1945b). El otro Rosas. Claridad.

Gramuglio, M.T. (2013). Una década dinámica. Protagonistas, transformaciones y debates en la literatura argentina de los años treinta. En Nacionalismo y cosmopolitismo en la literatura argentina. Editorial $\mathrm{Mu}-$ nicipal de Rosario.

Hernández Toledo, S. (2020). Entre Babel y Babel. Proyectos editoriales y culturales de Enrique Espinoza en Argentina y Chile (1928-1939). Meridional. Revista Chilena de Estudios Latinoamericanos, 13, pp. 65-90.

Korn, G. (1997). El hombre de los pájaros. El ojo mocho, 11, pp. 67-69.

Löwy, M. (2006). La estrella de la mañana: surrealismo y marxismo. El Cielo por Asalto.

Parson, G. (2007). Luis Franco: un intelectual oculto. Sarquis.

Rojo, A. (2012). Los orígenes del trotskismo argentino: de los años 30 al surgimiento del peronismo. Elaboraciones teórico-politicas y vínculos con la clase obrera. Archivos de Historia del Movimiento Obrero y la Izquierda, I, 1, pp. 103-125.

Saítta, S. (2001). Entre la cultura y la politica: los escritores de izquierda. En A. Cataruzza (dir.), Nueva Historia Argentina, vol. VII: Crisis económica, avance del estado e incertidumbre politica (1930-1943). Sudamericana.

Saítta, S. (2005). Presentación a Contra. La revista de los francotiradores. Universidad Nacional de Quilmes.

Sarlo, B. (2020). Una modernidad periférica. Buenos Aires, 1920 y 1930. Siglo Veintiuno.

Tarcus, H. (1996). El marxismo olvidado en la Argentina: Silvio Frondizi y Milcíades Peña. El Cielo por Asalto.

Tarcus, H. (2002). Mariátegui en la Argentina, o las politicas culturales de Samuel Glusberg. El Cielo por Asalto. 
Tarcus, H. (2009). Cartas de una hermandad. Leopoldo Lugones, Horacio Quiroga, Ezequiel Martinez Estrada, Luis Franco, Samuel Glusberg. Emecé.

Tarcus, H. (2019). En arte, todo está permitido. Vicisitudes del Manifiesto por un arte revolucionario independiente. En Manifiesto por un arte revolucionario independiente. Siglo Veintiuno.

Tula, J. (2000). Vida y muerte en la poesia de Luis Franco. Letralia. Revista de los escritores hispanoamericanos en internet, 90.

Viñas, D. (2007). Luis Franco: de Lugones a la heterodoxia. Prólogo a Luis Franco, El general Paz y los dos caudillajes. Sarquís. 